The University of Akron

\title{
IdeaExchange@UAkron
}

Proceedings from the Document Academy

University of Akron Press Managed

January 2016

\section{Analyzing the PVCs Documents: A Multimodal Rate-based Approach to Understand Community's Goals and Values}

\author{
Anastasia Sergeeva \\ ITMO University, an.se.sergeeva@gmail.com \\ Bogdan Kirillov \\ ITMO University, k1r1llov@bk.ru \\ Ekaterina Voronina \\ ITMO University, voroninaeu@gmail.com
}

Please take a moment to share how this work helps you through this survey. Your feedback will be important as we plan further development of our repository.

Follow this and additional works at: https://ideaexchange.uakron.edu/docam

Part of the Communication Technology and New Media Commons, $\underline{\text { Critical and Cultural }}$ Studies Commons, and the Digital Humanities Commons

\section{Recommended Citation}

Sergeeva, Anastasia; Kirillov, Bogdan; and Voronina, Ekaterina (2015) "Analyzing the PVCs Documents: A Multimodal Rate-based Approach to Understand Community's Goals and Values," Proceedings from the Document Academy: Vol. 2 : Iss. 1 , Article 15.

DOI: https://doi.org/10.35492/docam/2/1/15

Available at: https://ideaexchange.uakron.edu/docam/vol2/iss1/15

This Conference Proceeding is brought to you for free and open access by University of Akron Press Managed at IdeaExchange@UAkron, the institutional repository of The University of Akron in Akron, Ohio, USA. It has been accepted for inclusion in Proceedings from the Document Academy by an authorized administrator of IdeaExchange@UAkron.For more information, please contact mjon@uakron.edu, uapress@uakron.edu. 


\section{Introduction}

The emergence of professional virtual communities (PVCs) has provided a solution, new ways and techniques into knowledge management and sharing both in organization and professional settings. Rapid growth and extensive exchange of information and knowledge through different kinds of virtual communities has provide a whole new world of professional development and growth. Community members share their ideas, thoughts and solutions, solve professional problems, improve individual skills, search for a cooperation and create innovations. But here is a question: do the members of these communities use the community only as a professional guide in their field, or there are other goals and interests, which help the community to function and develop? To find the answer, we need to look closely to the both external and internal structure of community communication, and first of all - what are the communities main goals in values in terms of user's choice of topics and what "secret rules" they use to communicate to each other and to foster the sense of community shared between the members.

\section{Professional Virtual Community}

Virtual Communities (VCs) are historically described as places on the web where people can find and then "talk" to others with similar interests, using the Internet sites, resources and protocols. One of the fist classifications by Whittaker, Issacs and O'Day (Whittaker et al.1997 ) identifies core attributes of VC includes a shared goal, repeated, active participation, emotional ties, shared activities among participants, access to shared resources, reciprocity of information, support and services among members, shared context of social conventions, language and protocols et.c. The slightly different scheme proposed by Lazar and Preece (Lazar, Preece, 1998) includes three major features to distinguish the VC's: attributes of VCs (shared goal or interest, shared activities among community members, access to shared resources et.c), supporting software (Newsgroups, Bulletin boards, Internet relay chat, forums...), their relationship to physical communities (communities based on physical communities (local forums), communities somewhat based on physical communities (hobby-based communities, sports communities), and purely online communities where members prefer anonymity (support communities, some chats and boards) and sociological concept of boundedness (tightly bound in the company's intranet or loosely bound as in most internet communities).

According to Lee there are four main features for a successful virtual community. These features include the following: a virtual community must 
be constructed based upon a computer-mediated space (cyberspace), the main driving force of the community's activity and the main communication channel is information technology; participants of a virtual community determine the topics and contents of a virtual community's communication; contacts among members promote and foster the relationships within a virtual community. (Lee et al., 2002, Tamjidyamcholo et al., 2014). Y. Zhang, S.R. Hiltz (Y. Zhang, S.R. Hiltz,2003) and Andrews (Andrews,2002) agreed about mixed motivation of people who come to a virtual community: not just seeking information or knowledge and solving problem, but also a place to meet other people, to seek friendship, sense of community and affiliation. Butler explained four types of individual benefits from the participation in virtual community: information benefits (access to useful information), social benefits (social affiliation and support), visibility benefits (professional reputation growing and retesting), and altruistic benefits (joy of helping others) (Butler et al. 2002).

Professional virtual communities (PVCs, there also very similar term Virtual Communities of Practice (VCoPs) which have the same definition, sometimes the PVC define as a subclass of VCoPs (Dudezert et al.,2006) are different in some ways from general virtual communities. Wenger defines a professional virtual community as an expanded community with a shared activity (Wenger, 1998, Tamjidyamcholo et al. 2014), stresses that the main difference from ordinary virtual community is its users common professional background. Chen and Hung propose what a key achievement of PVCs is to presentation of novel insights and frameworks for knowledge sharing and management at the institutional context (Chen and Hung, 2010). Participants start to communicate in PVCs trying to solve their professional problems and presents some solutions to the other participants, thus grow their expertise in a professional field.

During the last decades, many commercial and non-commercial institutions started to facilitate growth of such a communities inside their professional field, considering them as an effective tool for the development not only inside particular organization, but for the broader area of professional expertise. Hagel considers a professional virtual community as a virtual community with common interests. Such a community aim to gathers people with shared expertise and knowledge about a particular professional area (medicine, IT, teaching e.t.c). Simillarly, according to Bressler and Grantham (Bressler and Grantham, 2000) professional virtual community brings together individuals with similar interests who cooperate with each other in order to accomplish common goals. 
Boughzala and Kaouane (Boughzala and Kaouane, 2004) describe the lifecycle of PVC's as a 6-staged process, includes Emergence, Structuration, Maturation, Officialisation, Consolidation and Evolution stages; through the constant process of changes the community firstly emerges around some purpose, or idea, then grows larger and becomes useful and well-structured and at the end of the lifecycle regroups to the new task.

Katzy and Ma classify virtual professional communities into intra-firm, inter- firm and public professional communities (Katzy and Ma, 2002). Intrafirm communities have the purpose to improve knowledge sharing among employees of only one organization, the inter-firm communities provide link between different organisations and/or between organisations and their customers and public professional communities usually open to all qualified professionals in some area. Followings Dudezert and Lefebvre, Roos and Sardas (Dudezert et al. 2006) we propose two main research areas in the field of PVC analysis. The first of them deals with communities structure and operations, the second is about learning (and how to increase the learning process and knowledge sharing) inside the community.

\section{PVC's Members Behaviour}

Despite the fact that the user's behaviour inside the PVC's can change through the time and depends on numbers of community organization's factors and growth of expertness, there are some ways to divide the participants to different groups according to their participating activity. Chang (Chang et al 2009), Gabbay and Le May (Gabbay and Le May, 2009) and VázquezBronfman (Vázquez-Bronfman ,2011) show that some people invested more to learning from and communicate with other members, and others only want to be informed about some results or just to receive an answer to their questions. Based on that fact, Chang (Chang et al.2009) and Gabbay and Le May (Gabbay and Le May, 2009) show the three levels of participating in community. The first level is the core group of active members of community (approximately 15\% of community), The second group is regular members, but not so active as previous group (15 - 20\%), the last one is peripheral group - the group without active participation, limited readers and users (not creators) of information. There are also a number of researches show a positive link between frequency of active using PVC and users satisfaction of the PVC's (Anandarajan, Igbaria, \& Anakwe, 2002, Jiménez-Zarco et al. 2014) which corresponds with user's visibility benefits discussed early. 


\section{Community's Values}

Following Oyserman (Oyserman, 2015). we describe values as an internalized cognitive structures that guide choices by evoking a sense of basic principles of right and wrong, a sense of priorities, and a willingness to make meaning and see patterns. Like other cognitive constructs, values can be studied at the individual level or at the group level: values are internalized social representations and moral beliefs, which guide the person's course of actions, values are also internalization of sociocultural goals that provide a means of self-regulation of impulses and values are scripts or cultural ideals held in common by members of a group; the group's 'social mind. Therefore every developed society, both in real world and in the Internet has their own set of values, which helps to regulate the behaviour of community members and to increase the number of social links between the members. And, if we speak about virtual communication, the community values have always presented in community verbal and text production (such as posts, comments, articles, forum messages etc).

\section{Hypotheses}

In order to understand the community's goals and values we can derive the following hypotheses:

1. The network of "Follower-followee" connections is a power-law graph. According to Janssen and Pralat (Janssen, Prałat 2010) a network with a ranking scheme for nodes obeys the power-law degree distribution, and Habrahabr already has two built-in ranking schemes: karma and rating.

2. The top of the network consists of not only IT-professionals but a people with different fields of expertise. We think so, because IT is related to many other fields like Physics, Mathematics, Business, Art et c. and participants have different backgrounds. We also think that these non-IT participants will be in the top of network, maybe if their background is related to the Habrahabr values.

3. We can find a different types of active/passive behaviour in the community, there are significantly different number of people, includes in that classes.

4. There are specific discourses about the "others", which can be used to consolidate the community and construct the group identity.

5. There are a lot of profession-oriented topics, which involve a lot of professional terminology as well as some words to describe a profession-oriented cognitive concepts and processes 


\section{Methods and Sample The PVC Description}

In our current research we focus on the biggest Russian IT PVC called Habrahabr (placed at habrahabr.ru). The community starts at 2006 and contains 596371 users at the moment of research, but the most part them has a read-only account. This explains by Habrahabr rules: the person achieves rights to write comments and posts only after the invitation procedure from other users (who have a limited numbers of invitations) or after the publishing the a high-rated post in a special Habrahabr inner blog (called "the Sandbox"). Approximately $85 \%$ of users are registered as males, $6 \%$ - as females and $13 \%$ used no gender. According to site the community's primary goals are professional development and information sharing between users, specialized in IT. Recently, after we finished extracting the information from the resource, the Habrahabr's management decided to divide the content and (partly) user's community for a three semi-independent sites in order to "purify" the strong IT-related topics from other popular technical, science and management content. We discuss this decision and its consequences in the conclusion.

\section{Methods}

Social network analysis

In this research we use several SNA methods to investigate the structure of "Follower-Followee" network.

To determine the type of network and form of its degree distribution, we use two approaches: qualitative and quantitative. The qualitative approach is based on plotting complex network portrait (Bagrow et al. 2008). This method allows us visually narrow down a scope of possible complex network types to a particular family. The quantitative approach is based on calculating the Kolmogorov-Smirnov goodness of fit test for power law distribution (Clauset et al., 2009) via igraph package(Csardi, Nepusz, 2006). From that we can get a power for the power law.

To measure significance of a node we use PageRank, HITS and betweenness centrality (calculated via igraph).

Betweenness centrality (Freeman, 1979) of a node is defined as the fraction of shortest paths between node pairs(excluding that node) going through that node. It is often used as measure of significance in epidemiology(Christley et al.,2005).

PageRank is a random-walk algorithm developed by Brin and Page at Google. It is used by Google as way to rank results of the web search(Brin and Page, 1998). 
HITS - Hyperlink-Induced Topic Search (Kleinberg, 1999) separates nodes into two groups: authorities(high indegree) and hubs(connected to many authorities), thus allowing us to use two types of significance measure.

To identify correlations between user characteristics (karma, number of posts, votes and comments) and node characteristics(indegree, outdegree, betweenness, PageRank, HITS hubs and authorities) we use Spearman's rho method implemented in pspearman R package (Savicky, 2014). To plot the correlation matrix we use the corrplot package (Taiyun, 2013). Inside of the analysis script we use plyr R package (Wickham, 2011) for inner joins and arrangements.

\section{Classification}

To classify the users by their user and node characteristics we came up with the following scheme:

We classify users by three characteristics(eight possible classes): indegree, outdegree and number of comments, according to its value compared to median of respective characteristic. For example, we attach user $U$ to class 001 if U's indegree and outdegree are lower than indegree and outdegree median.

This classification gives an useful insight into the behavior of the user. The indegree is a measure of the user's value as a source of information. The outdegree - as a sink of information capacity. The number of comments shows how readily the user participates in interpersonal communication. The $3 \mathrm{~d}-$ scatterplots of classes are plotted via scatterplot3d (Ligges and Mächler, 2003).
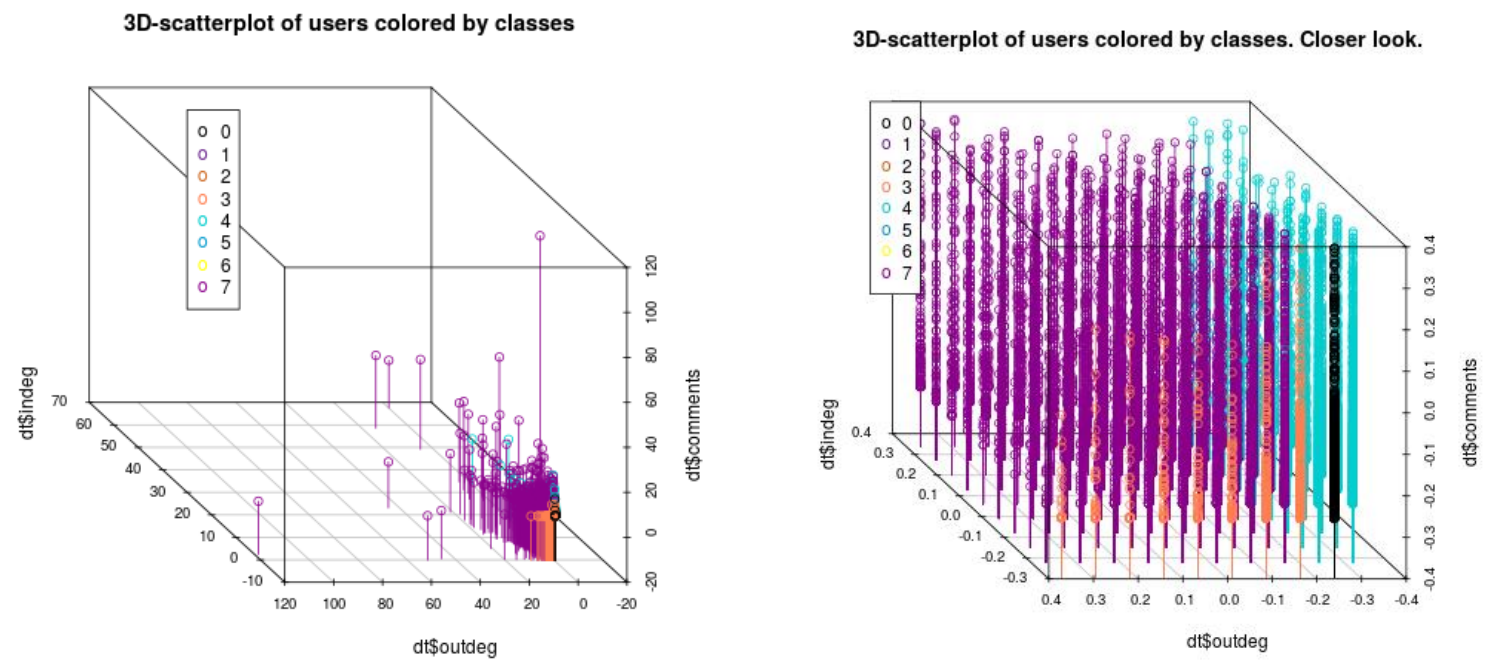


\section{Linguo-Statistical analysis}

In current research we used the word-frequency metrics and compare the results to the same words frequencies in http://bokrcorpora.narod.ru/frqlist/frqlist-en.html (The frequency dictionary for Russian).

\section{Discourse Analysis}

We used the CDA (Critical discourse analysis) version of discourse analysis, focusing on the larger social practice of modern Russian IT-discourse (both inside and the outside of IT-community) to identify the groups, (possibly) oppressed by the community's members (Janks,1999) and made a classification of statements about "Others".

\section{Results}

\section{Complex Network Structure}

The "Follower-followee" network is a power-law graph with the power equal to 2.86911420522329 ( $\mathrm{p}$-value $=0.983153198384792$ ), which is similar to the Barabasi-Albert network which has the power equal to 3 . If we look at the portraits of Habrahabr and BA networks, we will see the similar patterns.

Portrait of Barabasi-Albert network was obtained from http://people.clarkson.edu/ dbenavra/B_matrix_site/. The Habrahabr network obeys the preferential attachment rule, because it is similar to BA.
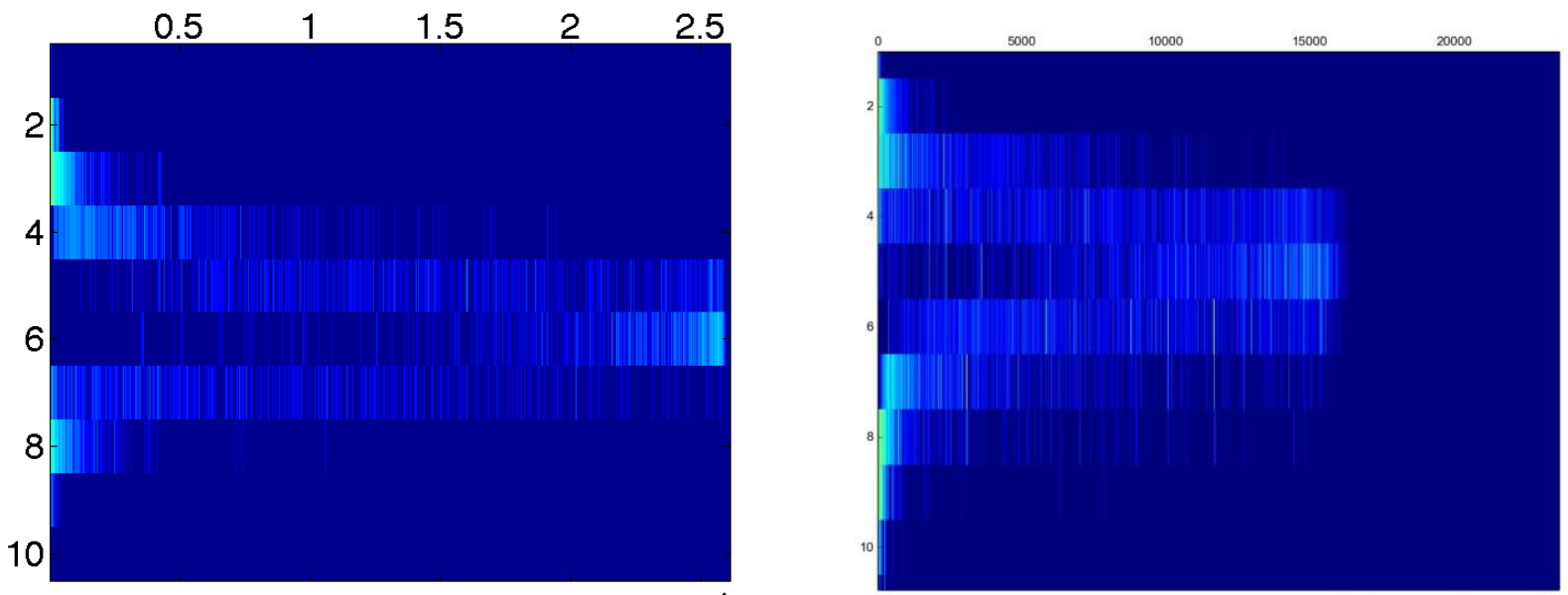

The first one is the Barabasi-Albert network portrait and the second is Habrahabr network portrait. 


\section{User and Node Characteristics Correlations}

There are a lot of significant ( $\mathrm{p}$-value smaller than 0.05) positive correlations between node and user characteristics. The strongest three are between number of comments and indegree(0.68), PageRank(0.66), HITS hubs(0.63). The weakest three are between HITS authorities and number of posts $(0.06)$, karma(0.07) and number of votes $(0.08)$. There are no negative correlations.

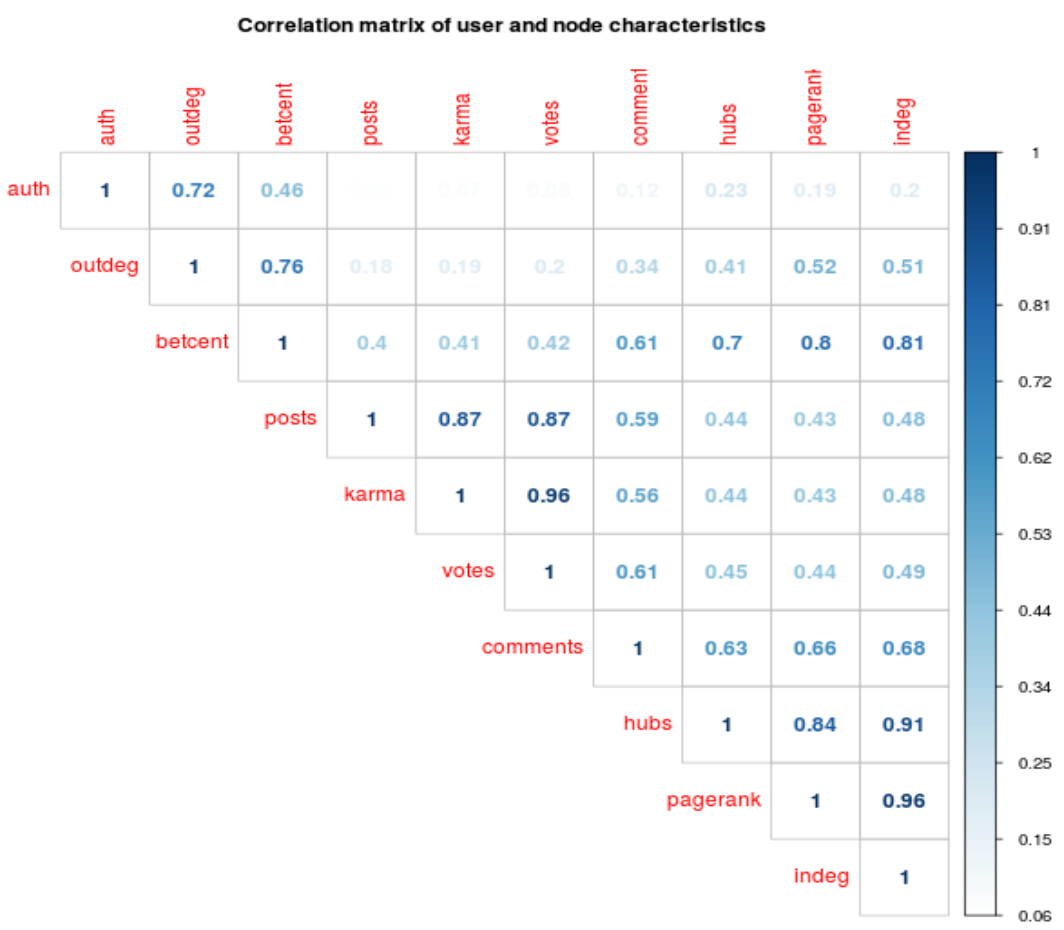




\section{User Classification}

Using the classification scheme we came up with these classes:

\begin{tabular}{|l|l|l|l|l|l|}
\hline Class number & Indegree & Outdegree & Comments & Class name & Class size \\
\hline 0 & 0 & 0 & 0 & mass & 11491 \\
\hline 1 & 0 & 0 & 1 & talkers & 0 \\
\hline 2 & 0 & 1 & 0 & readers & 0 \\
\hline 3 & 0 & 1 & 1 & $\begin{array}{l}\text { readers- } \\
\text { talkers }\end{array}$ & 5145 \\
\hline 4 & 1 & 0 & 0 & writers & 12994 \\
\hline 5 & 1 & 0 & 1 & $\begin{array}{l}\text { writers- } \\
\text { talkers }\end{array}$ & 0 \\
\hline 6 & 1 & 1 & 0 & $\begin{array}{l}\text { readers- } \\
\text { writers }\end{array}$ & 0 \\
\hline 7 & 1 & 1 & 1 & activists & 19604 \\
\hline
\end{tabular}

We can consider indegree an ability to be interesting to read, outdegree - a tendency to read interesting people frequently and number of comments - a willingness to participate in conversations with others. With the former considerations in mind, we observe strict patterns in user behaviour: we can strictly divide those classes as active in writing posts and in conversation(writers + readers-talkers), active in every form of activity (activists) and passive (mass). We do not observe boundary behaviour (for example talkers - eager to write comments, but they don't read and they are never read; writers-talkers - write only posts and comments, but don't read anything; or readers-writers - don't participate in conversations). These three types of activity(writing interesting stuff, reading posts and comments of the others and commenting the posts) are strongly connected: one does not talk(write comments) about something he did not read (unless he/she is a troll or spammer), one also does not usually write his/her own posts and comment only posts he/she had written. It is also not common for user to write and read posts, but don't talk about them with others in the community.

\section{Non-IT People at the Top of PVC}

To find how many IT-unrelated users there are at the top of the network we evaluated the users at top-100 of all node characteristics. After removing 
duplicates we were left with 199 users. For each user we have looked through their profile and tried to deduce his/her field of expertise. We found 22 different fields. The fields of Marketing, Business, Science, Engineering, Management, Media, Design, Celebrity (special group for people held as celebrity by the community), Medicine and Government are considered ITunrelated. The fields of Web, Information security, Software development, System administration, Interface design, Usability, Testing, Game development and Other IT. The users whose field we failed to identify were tagged Unknown, this group was excluded from the analysis. The groups Habrahabr and Company blog were considered too broad therefore excluded from the analysis. So, we were left with 161 users. Almost half (72) of them are IT-unrelated, the other 89 - IT-related.

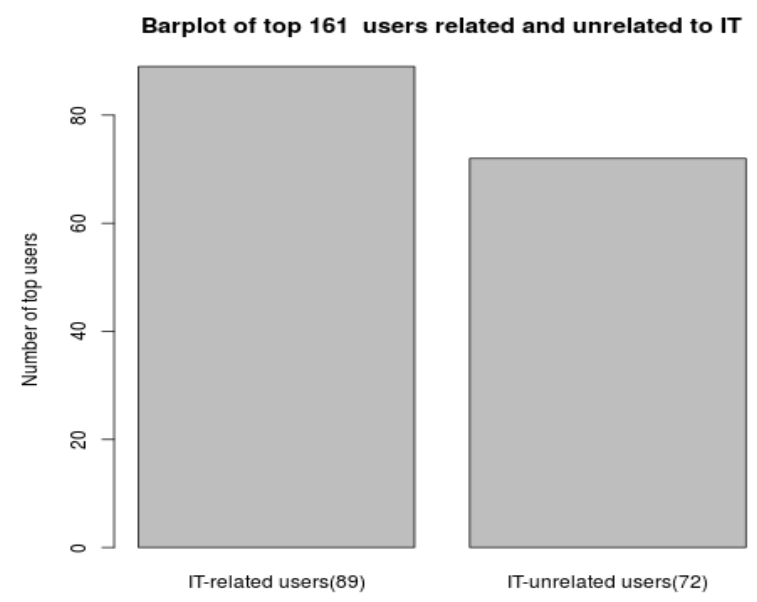

\section{Linguistics Content of PVC's Communication}

For a research purpose we created a corpus based on 4355916 words from user's comments. We compare the corpus to the modern Russian frequency dictionary http://bokrcorpora.narod.ru/frqlist/frqlist-en.html (based on 50000 000 words). After evaluating frequencies of the most popular words in our list (the words which have both high absolute and relative frequencies) we found these key features describing the prime content of the communication:

- we have a very highly ranked nouns defining the key concepts of everyday programmers work such as "code" (and "coder"), "program" ("programmer"), “soft”, “data”, “driver”, “algorithm”, “user”, "server", "processor" etc. It shows us that the communication inside the community is highly profession-oriented. It also includes a lot of concepts and processes from the user's everyday life 
- there are a lot of top-ranked verbs, which can be divided in three big groups, the first one is connected with current topic/paper, which generates the discussion ("to read", "to write", "to understand"), the second one presents the processes of thinking and creation of knowledge or a product ("to know", "to create", "to realize") and a third one is about current processes at work ("to code", to implement").

- the using of adjectives is very limited and mostly concentrated in "good-bad" dichotomy. This is also can be described in terms of professional-orientedness of communication inside the community and preferences of clear, non-emotional description of problems and results The results supports the hypothesis about highly profession-oriented content of Habrahabr's communication and the typical processes of topics discussions and work-related problem solving in the communication

\section{Concept of "Others" in PVC \\ Discourse About "Women"}

Based on statistical information about the community's gender composition and a previous works which describe the Russian IT-community as mostly male-oriented (ИД «Компьютерра», 2003, Girls in ICТ 2012), we created a corpus of comments, which included the terms "girl" and "woman" and a number of synonyms and randomly took the 200 comments at the closer look. We used a number of bimodal scales, which represents the main topics, invoke the terms. Analyzing the content of the messages we found the following:

- there are three major groups of topics; which include term "woman" as a key concept to the comment; the first one is about contrasting men ("us") and women ("them") as possessing different kinds of personal and professional interests, talents and intellectual abilities (there was just a few comments, include opposite view of "women's similarity to the men", and these comments arose only as a contradiction to the previous statement) These comments usually not only contrast the sexes, but also stress the superiority of man's possessions. One of the most popular semi-type of this group is the topics about women's inability to be successful in IT area, especially in programming. The second group is objectification of women, presenting women (sometimes parts of their bodies) as just a sexual object without any personal features. The third major group of comments are about active denying the discrimination in IT. 
- if anybody in the community starts to protest against this highly misogynic way of thinking about women (usually by storytelling about remarkable women who break these stereotypes) the community denies this by presenting the concept of "unusual woman" - a person different from other women therefore not a woman at all in terms of community's definition.

- the most topics, invoking the "women's theme" use irony or sarcasm towards the object. It helps to create a "not a person" view of women and also can be used by community members as an excuse to very inhumanistic statements.

\section{Discourse About Humanities Majors}

As a starting point in search for the next "Them" group on Habrahabr.ru we used popular Russian statements about inevitable rivalry between people with different professional education (especially betwenn techs and humanities majors). Because of (mostly) tech-oriented nature of the PVC and number of chosen non-IT topics and users we discussed in the previous sections, we expected rather few people with a strictly non-technical background within the community and unpleasant, caricature image of them. We used the same procedure as in our previous study of "women" concept, but in this time we added a special "liking" metrics to evaluate the average favouring of comments groups by community members. Using the categorization procedure and evaluation by experts we found the following:

- The major part of topics involving humanity's major describes this person as a complete stranger, with different (inferior) type of mind and very irrational behaviour; but there is a sufficiently big corpus of apologetic statements about the group (much bigger than in women's case)

- There is a tendency to use this term as synonymous to the lay people, commoners compared to intellectual and knowledgeable people from IT and other technical fields.

We have also compared the harsh statements about "humanitarians" to less abundant apologetic ones using the median metrics of average "liking" of comments, and found the higher level of approval to the "humanitarian are stupid" statement than the contrast position.

Comparing these two outcasts groups we can support the hypothesis about complex and well-developed concept of "other" people and groups outside the community, which can be portrayed in a highly caricature way in order to consolidate the community by comparing "them" to "us" (to the proper PVC 
members). Those images order the community members to speak about the subjects in such manner. The complex nature of others image also may serve as sign of the community's maturity.

\section{Discussion and Conclusion}

This study uses an integrated multi-modal approach to PVC analysis with the main focus on the processes of ranking and evaluation used by community members to rate the statements of other members, the members themselves and people outside the community. We want to stress two main findings that deserve considerable attention both in case of scientific research and in a practice of PVC design and support. The first one is that despite the fact that the communication is highly profession-oriented, there are a lot of very popular IT-unrelated participants and unspecialized topics (but the range of those topics is restricted by the community). These topics represent the typical interests of community members alongside with the main values; there is also a possibility of these topics serving integral function, helping "glue" community together by appealing to the high-level community culture's values thus intensifying the linking inside the community. Recently the community management decided to split the community into three parts (and three different sites), basing on the formal content of topics (It-topics, "Hobby"-topics and management topics); the decision raised negative reaction from users and followed to the diminishing the number of comments and views of Habraharb's pages, but we're not sure is the effect temporary or permanent. The second important finding is a very harsh and complex image of "others" inside the community. The image includes supporting aggression towards the people outside the community (both in professional and a smaller PVC's senses) which harms effective interprofessional contacts and interferes with the integration of outcasts (for example, women-programmers) in the community. We think this image needs to be destroyed for the community to be more open and effective.

\section{References}

Anandarajan, M., Igbaria, M., \& Anakwe, U. P. (2002). IT acceptance in a less-developed country: A motivational factor perspective. International Journal of Information Management, 22, 47-65.

Andrews, D. (2002) Audience-specific online community design. Communications of the ACM, 45(4), 64-68

Bagrow J. P. , Bollt E. M., Skufca J. D., ben-Avraham D.,(2008) Portraits of complex networks, EPL (Europhysics Letters), 2008, 81, 6 
Boughzala I., Kaouane F.(2005) : Vers un cadre méthodologique pour la conception des communautés professionnelles virtuelles, 10ème colloque de l'AIM, 21-23 septembre 2005, Toulouse, France by Dudezert A., Heibült H. and Boughzala I.(2006) Virtual professional communities and their role for knowledge management AIM 2006 - Information Systems and Collaboration: State of the Art and Perspectives, Best Papers of the 11th International Conference of the Association Information and Management (AIM), Luxembourg, June 8-9, 2006

Bressler S.E, Grantham C. (2000) Communities of commerce: building internet business communities to accelerate growth, minimize risk, and increase customer loyalty. McGraw-Hill Professional

Brin S., Page L.(1998) The anatomy of a large-scale hypertextual Web search engine, Proceedings of the seventh international conference on World Wide Web 7, p.107-117, April 1998, Brisbane, Australia

Butler B.S., Sproull L., Kiesler S., . Kraut R.(2002) Community effort in online groups: who does the work and why? in: S. Weisband (Ed.), Leadership at a Distance, Lawrence Erlbaum Associates, New Jersey, 2002.

Chang, J., Chang, W., \& Jacobs, R. (2009). Relationship between participation in communities of practice and organizational socialization in the early careers of South Korean IT employees. Human Resources Development International, 12(4), 407-427

Chen C-J, Hung S-W. (2010) To give or to receive? Factors influencing members' knowledge sharing and community promotion in professional virtual communities. Information \& Management 2010;47(4), $226-236$

Christley M.P., Pinchbeck G.L., Bowers R.G., Clancy D , French, NP , Bennett, R and Turner, J (2005). Infection in social networks: using network analysis to identify high-risk individuals. Am. J. Epidemiol, 162 (10). 10241031

Clauset A., Shalizi C.R., and Newman M.E.J. (2009), "Power-law distributions in empirical data" SIAM Review 51(4), 661-703

Csardi G, Nepusz T (2006): The igraph software package for complex network research, InterJournal, Complex Systems 1695. 2006. http://igraph.org

Dudezert A., Heibült H. and Boughzala I.(2006) Virtual professional communities and their role for knowledge management AIM 2006 Information Systems and Collaboration: State of the Art and Perspectives, Best Papers of the 11th International Conference of the Association Information and Management (AIM), Luxembourg, June 8-9, 2006 
Fellows I. (2014). wordcloud: Word Clouds. R package version 2.5. http://CRAN.R-project.org/package=wordcloud

Freeman, L.C., (1979) Centrality in networks: I. Conceptual clarification. Social Networks 1, 215-239

Gabbay, J., \& Le May, A. (2009). Practice may perfect: Discovering the roles of community of general practice. In A. Le May (Ed.), Communities of practice in health and social care West Sussex: Wiley-Backwell. 49-65

Gupta S., Kim H.W., (2004), "Virtual Community: Concepts, Implications, and Future Research Directions", in Proceedings of the 10 American Conference on Information Systems, August, New York, USA, $2679-2687$

Janks, H. (1999) Critical Discourse Analysis as a Research Tool. In Marshall, J. and Peters, M. (Eds). Education Policy. The International Library of Comparative Public Policy. Cheltonham, UK: Elgar. Chapter 4. 49-62

Janssen J., Pralat P. (2010) Rank-based attachment leads to power law graphs, SIAM J. Discrete Math. 24, 420-440

Jiménez-Zarco A.I., Gonzalez-González I.,Saigí-Rubió F., TorrentSellens (2014)The co-learning process in healthcare professionals: Assessing user satisfaction in virtual communities of practice Computers in Human Behavior 12/2014; 51(2):1303-1313

Katzy B.R., Ma X. (2002) : Virtual Professional Communities Definitions and Typology, Proceedings of the International Conference on Concurrent Engineering, Rom, 14.-16. June, 2002.

Kleinberg, J. (1999). "Authoritative sources in a hyperlinked environment Journal of the ACM 46 (5): 604-632

Lazar, J. and Preece, J. (1998) Classification scheme for online communities, Proceedings of the Fourth Americas Conference on Information Systems, Baltimore, MD, 84-86

Lee F.S, Vogel D, Limayem M. Virtual community informatics: what we know and what we need to know; 2002. Paper presented at the System Sciences, 2002. HICSS. Proceedings of the 35th Annual Hawaii International Conference on.

Ligges, U. and Mächler, M. (2003). Scatterplot3d - an R Package for Visualizing Multivariate Data. Journal of Statistical Software 8(11), 1-20.

Oyserman, D. (2015). Values, psychological perspectives. In Wright, J. (Editor-in-chief) International Encyclopedia of the Social and Behavioral Sciences, Vol 22, 2nd Edition 1-5

Savicky P. (2014). pspearman: Spearman's rank correlation test. R package version $0.3-0$ 
Taiyun W.(2013) corrplot: Visualization of a correlation matrix. R package version 0.73. http://CRAN.R-project.org/package=corrplot

Tamjidyamcholo, A., et al. (2014). "Evaluation model for knowledge sharing in information security professional virtual community." Computers \& Security 43: 19-34.

Wenger E (1998). Communities of practice: learning, meaning, and identity. Cambridge University Press

Whittaker, S., Issacs, E., and O'Day, V. (1997) Widening the Net: Workshop report on the theory and practice of physical and network communities, SIGCHI Bulletin, 29, 3, 27-30

Wickham H. (2011). The Split-Apply-Combine Strategy for Data Analysis. Journal of Statistical Software, 40(1), 1-29. URL http://www.jstatsoft.org/v40/i01/

Zhang, Y., \& Hiltz, S. R. (2003). Factors that influence online relationship development in a knowledge sharing community. In Proceedings of the ninth American conference on information systems, 410-417

Блестящие будущие возможности в сфере ИКТ для нового поколения женщин by International Girls in ICT - 2012 URL http://girlsinict.org/what-girls-ict-day

ФРАГМЕНТЫ ОТЧЕТА ОБ АНАЛИТИЧЕСКОМ ИССЛЕДОВАНИИ по теме: «Анализ тенденций развития ИКТ и их применение в социально-экономической сфере), ИД «Компьютерра» 2003 URL http://www.silicontaiga.ru/article/files/2074_1.pdf 